\title{
REVIEW OF THE HARD-FACING TECHNOLOGY sciendo APPLICATION FOR REPARATION OF THE GIVEN PARTS IN VARIOUS BRANCHES OF INDUSTRY
}

doi:10.2478/mape-2018-0035

Date of submission of the article to the Editor: 03/2018

Date of acceptance of the article by the Editor: $06 / 2018$

MAPE 2018, volume 1, issue 1, pp. 279-285

Vukić Lazić,

Dušan Arsić

University of Kragujevac, Serbia

Milan Mutavdžić

High Technical School, Leposavić, Serbia

\author{
Ružica Nikolić \\ Jozef Meško \\ University of Žilina, Slovak Republic
}

\author{
Ljubica Radović \\ Nada llić \\ Military Technical Institute, Belgrade, Serbia
}

\begin{abstract}
This paper deals with the problem of defining the optimal procedure for reparation of the machine parts of large dimensions and complex shapes. The procedure consists of establishing the causes of the part's damages, definition of the reparation technology, with selection of its parameters and ways of execution. The reparation is done by hard-facing, with heat treatment that consists of preheating, additional heating and the post hard-facing tempering. The process parameters' selection includes choosing the right filler metal(s), ways and order of depositing the hard-faced layers, ways of reaching and maintaining the preheating temperatures, checking of the base metal's chemical composition and mechanical properties and deciding on the post-process heat and mechanical processing of the executed hard-facing. The executed reparation of the forging hammer's mallet, presented in details, serves as an example how the reparation can successfully serve as a substitute for procuring the new part and thus producing the savings both directly in lower costs and indirectly in shortening the down-time of the damaged part operation.
\end{abstract}

Keywords: regeneration, hard-facing, friction, wear, machine parts

\section{INTRODUCTION}

Investigation of causes of machines' and devices' damages has established the fact that in more than $50 \%$ of cases damages appear due to the tribological processes in regular exploitation conditions and thermal fatigue (Lazić, 2001). This is why for design of regeneration technology it is necessary to know the possible wear mechanisms of the coupled elements. There, one has to keep in mind that, besides for regeneration of parts worn in normal operation, the hard-facing is used for regeneration of parts that suffered accidental fractures, as well as for the new cast parts manufactured with flaws. Hard-facing of the new parts is gaining an increased significance. The necessary hardness of the surface layers of those new parts is achieved by depositing the hard alloys, instead of by the classical heat treatment methods. All the aforementioned has contributed for the hard-facing to play the important role in the so-called advanced technologies. 
The responsible parts of machines, assemblies or devices are usually made of expensive alloys, thus by reparation, besides the shortening the down-times due to repairs, the savings are achieved both in the expensive base metal and in machining the parts to final dimensions. Economically the most justified is to regenerate the damaged parts by some of the welding methods. In the majority of cases, the criterion for performing the reparation is that the regeneration costs of the part do not exceed the price of manufacturing the new part. This is particularly important for the parts of large dimensions and in the batch production, while for the unique machines and devices the reparation is done regardless of the costs.

\section{BASIC CAUSES OF MACHINE SYSTEMS DAMAGES}

The notion of wear implies the loss of material from the contact surfaces caused mainly as a result of the mechanical forces action. Chemical processes, which accompany these phenomena, can sometimes be the basic cause of wear due to action of corrosion. Wear is a consequence of friction or common action of friction, thermal, chemical, electrochemical and other factors, on elements of the tribo-mechanical system, i.e. on their contact surfaces. Loss of material causes change of the shape and characteristics of the mechanical system elements, thus causing change of their functional characteristics.

In considering the wear, the factors that are primarily considered are those that are dominant in the given working conditions, like: material, quality and properties of the contact surfaces, properties of the relative motion between the contact surfaces, magnitude of loading, quantity and properties of particles created during the wear, etc. Thus, wear influences the change of shape and characteristics of the system's elements, where one of the wear types can be dominant: abrasive, adhesive, erosive, cavitation, fatigue, vibrational and combined.

\section{REVIEW OF THE HARD-FACING PROCESSES}

Hard-facing, whether manufacturing or reparatory, can be techno-economically justified only with the rational selection of the hard-facing process, filler metal, technology and the control methods.

All the welding by melting processes can be applied for the hard-facing: gas, manual arc, in protective atmosphere, powder or dross shielded, plasma, electro-vibration; in the recent times hard-facing is also done by electron beam, laser beam and friction.

During the hard-facing, in majority of processes, it is necessary to take into account the degree of mixing, which is the biggest in the first layer, then significantly smaller in the second and third layer, what automatically implies the necessity of the multi-layer hard-facing.

The application area of hard-facing is very broad; hard-faced are various tools, gears, crackshafts, internal combustion engines, working parts of the construction machinery for soil processing, parts of the transportation means, rollers of the rolling mills, coating of vessels in the chemical industry etc. It is also applied for correction of the casting flaws on the cast pieces of steel, iron, aluminum, brass, bronze, etc.

The hard-facing is based on deposition of the filler metal layers, which are usually of the different chemical composition than the base metal for the cases of regeneration, and of the approximately the same composition for correcting the casting flaws, or when the molds and forging dies are repaired. The deposited coating, i.e. the hard-faced layer, is not taken into account in dimensioning the corresponding structural parts, i.e. it is not considered as the carrying cross-section.

Manual arc hard-facing (MAG) is still the dominant procedure, both for the reparatory operations and for depositing the hard-faced coatings on the working surfaces of tools and parts.

In reparation of the worn parts, or repeated hard-facing, it is necessary of remove the damaged metal by machining, especially if there are cracks, which can act as the stress concentrators. This hard-facing procedure is applied for parts of steel, cast iron, $\mathrm{Cu}$ and $\mathrm{Al}$ and $\mathrm{Ni}$ alloys etc. In the majority of cases, the MAG welding can be executed without preheating. However, in 
the cases of thick hard-faced layers deposition over the massive steel substrate with the carbon content above $0.35 \%$, the preheating is mandatory. However, the preheating is not necessary when the austenitic $\mathrm{Mn}$ steel is hard-faced, which hardens by the complex mechanisms under the impact cold workloads. This steel and its thin sheets, are hard-faced by the short layers, with minimum heat input and fast cooling of the deposited layers.

For materials that are prone to forming of cracks in the HAZ, the short layers are hard-faced in the width equal to 1 to 2 electrode diameters, what reduces the "dissolution" of the filler metal, inherent stresses and deformations. However, for materials of good weldability, the hard-faced layers are wide and deposited with high intensity current. When the large areas are hard-faced by hard alloys, it is recommended to deposit the plastic inter-layer, of the Ni or austenitic electrodes, in the form of separated welds. The following layers are then executed with the maximum allowed intensity current, with welds that overlap. In general, the plastic inter-layer is recommended also in the cases of the bigger difference in thermo-physical properties between the hard-facing alloy and the base metal, as well.

Hard-facing of cylindrical surfaces can be done by depositing the longitudinal layers, or in the case of larger parts by the circular welds. Usually, for axles and shafts, the first hard-faced layers are deposited to the diametrically opposite sides in order to balance the thermal deformations (Jovanović et al. 1996; Lazić et al., 2001).

\section{BASIC PRINCIPLES FOR SELECTION OF THE FILLER METALS}

In the majority of cases, the filler metal for hard-facing is selected based on the required properties of the hard-faced part and available equipment. In the case when the heat treatment cannot be executed after the hard-facing, the required properties of the hard-faced layers can be achieved by adequate selection of the filler metal's chemical composition. In the case that the device operates in the conditions of the increased corrosive actions, the filler metals are being selected exclusively based on the chemical composition, which depends on the corrosion type; in the cases of parts exposed to friction forces, the problem of the filler metal selection is significantly more complex. However, hardness and the chemical composition cannot be the only criteria for estimate of the coating material adequacy. A brief review of the most frequently used filler metals, resistant to wear, is presented in (Lazić et al., 2001; Arsić et al., 2015). The filler metals, resistant to wear and corrosion are grouped into six classes: steels, white cast irons, tungsten carbides, cobalt alloys, nickel alloys and copper alloys.

\section{DETERMINATION OF THE OPTIMAL TECHNOLOGY FOR REPARATION OF THE FORGING HAMMER'S MALLET}

\subsection{Analysis of the hammer mallet's base metal}

It was established, by chemical analysis, that the base metal is the low-alloyed tempering steel, which corresponds to steel $34 \mathrm{CrNiMo6}$ (DIN). The percentage share of individual elements is given in Table 1, (Lazić et al., 2009).

Table 1

Prescribed and analyzed chemical composition of (34CrNiMo6) steel

\begin{tabular}{|c|c|c|c|c|c|c|}
\hline \multicolumn{7}{|c|}{ Chemical composition, \% } \\
\hline & $\mathbf{C}$ & $\mathbf{S i}$ & $\mathbf{M n}$ & $\mathbf{C r}$ & $\mathbf{N i}$ & Mo \\
\hline Prescribed & $0.30-0.38$ & $0.15-0.40$ & $0.40-0.70$ & $1.40-1.70$ & $1.40-1.70$ & $0.15-0.30$ \\
\hline Analyzed & 0.35 & 0.27 & 0.45 & 1.25 & 1.64 & 0.22 \\
\hline
\end{tabular}

\subsection{Weldability estimate}

This steel belongs into a group of poorly weldable materials; besides the increased content of carbon ( $\mathrm{C}=35 \%>25 \%)$, it also contains the alloying elements $(\mathrm{Cr}$, Mo, Ni), which are improving the mechanical properties, but worsening the weldability. The weldability was evaluated according to the value of the chemically equivalent carbon (CE), (Jovanović et al. 
1996). Since the calculated value exceeded the recommended limit $(C E=45 \%)$ and taking into account the thickness of the part to be repaired, it was obvious that this steel must be preheated, additionally heated and subjected to high tempering during the welding.

The preheating temperature was calculated according to the Seferian formula for the thickness over $240 \mathrm{~mm}$, as $350^{\circ} \mathrm{C}$, (Jovanović et al. 1996). Since the preheating temperature cannot not be higher than $\mathrm{M}_{\mathrm{s}}$ temperature (about $310^{\circ} \mathrm{C}$ ), the adopted preheating temperature was $\mathrm{T}_{\mathrm{p}}=$ $300 \pm 10^{\circ} \mathrm{C}$. The previous experiences of these authors in reparation of the mallets have shown that the local preheating does not have any effect on massive parts, due to the "heat sink", that appears, (Lazić et al., 2009; 2014; 2016). This is why the whole mallet, of the $6000 \mathrm{~kg}$ mass, after elimination of cracks, is being preheated up to the calculated temperature. The additional heating is often done, since it is necessary to maintain the initial preheating temperature.

\subsection{Selection of the filler metal}

The basic electrode GALEB 70 (Ø3.25 and $\varnothing 4 \mathrm{~mm}$ ) was used for coating the groove, while for the groove filling the electrode PIVA 352 was applied. To increase the surface hardness of the sliding-guides zones, it was necessary to execute the several surface layers by the E DUR 300 electrode, Table 2. The recommended welding parameters are given in Table 3. Electrodes drying rate was $400^{\circ} \mathrm{C} / 1 \mathrm{~h}$.

\subsection{Selection of the reparation technology}

Prior to hard-facing, it is necessary to reach the crack tip by machining, i.e. to perform the "releasing" of all the flaws and create the optimal groove for welding. It is recommended to design the groove with the minimal weld's volume. It is also agreed to reach the "healthy" base metal by mechanical machining, thus creating the surface without cracks to which the missing portion of the mallet's volume would be hard-faced.

Table 2

Properties of the filler metals (Catalogues of electrode manufacturers)

\begin{tabular}{|c|c|c|c|c|c|c|c|c|c|c|c|c|}
\hline \multirow{2}{*}{$\begin{array}{l}\text { Electrode } \\
\text { mark }\end{array}$} & \multicolumn{6}{|c|}{ Chemical composition, \% } & \multirow[t]{2}{*}{$\begin{array}{c}\text { Current } \\
\text { type }\end{array}$} & \multicolumn{4}{|c|}{$\begin{array}{l}\text { Mechanical properties of the } \\
\text { hard faced layer }\end{array}$} & \multirow[t]{2}{*}{$\begin{array}{c}\text { Hardness } \\
\text { HB }\end{array}$} \\
\hline & C & Si & Mn & $\mathrm{Cr}$ & $\mathrm{Ni}$ & Mo & & $\begin{array}{c}\mathbf{R}_{\mathrm{m}} \\
\mathrm{MPa}\end{array}$ & $\begin{array}{l}\mathbf{R}_{\mathrm{eH}} \\
\mathrm{MPa}\end{array}$ & $\begin{array}{l}A_{5} \\
\%\end{array}$ & $\begin{array}{r}\mathrm{KV} \\
J\end{array}$ & \\
\hline GALEB $70^{\star *}$ & 0.08 & 0.70 & 1.50 & - & 0.7 & 0.20 & $=(+)$ & $\begin{array}{l}640- \\
710\end{array}$ & $>520$ & $>22$ & $\begin{array}{l}>125 \\
+20^{\circ} \mathrm{C}\end{array}$ & - \\
\hline PIVA $352 \mathrm{~B}^{\star}$ & 0.08 & 0.5 & 0.85 & 2.3 & - & 1.0 & $=(+)$ & $\begin{array}{l}640- \\
720\end{array}$ & $\begin{array}{l}540- \\
620\end{array}$ & $\begin{array}{l}19- \\
26\end{array}$ & $90-140$ & - \\
\hline E DUR $300^{\star *}$ & 0.18 & - & 1.30 & 1.2 & - & - & $=(+)$ & - & - & - & - & $280-330$ \\
\hline
\end{tabular}

The heat input influence on the output properties of the hard-faced samples was analyzed, with help of the TTT diagrams for this particular steel. Calculating the cooling time between $800^{\circ} \mathrm{C}$ and $500^{\circ} \mathrm{C}(\mathrm{t} 8 / 5)$, one can estimate the structure and hardness in the most critical zone - the HAZ. By entering this time into the TTT diagram, the hardness and structures were estimated and results are presented in Table 4 (Jovanović et al., 2001; Lazić, 2001; Lazić et al., 1997; 2016). 
Table 3

Recommended parameters of welding/hard-facing

\begin{tabular}{|c|c|c|c|c|c|c|}
\hline \multirow[b]{2}{*}{ Sample \# } & \multicolumn{4}{|c|}{ Electrode properties } & \multicolumn{2}{|c|}{ Heat treatment } \\
\hline & Mark & $\begin{array}{c}\text { Diameter } \\
\mathbf{m m}\end{array}$ & $\begin{array}{c}\text { Input } \\
\text { current } \\
\text { A }\end{array}$ & $\begin{array}{c}\text { Current } \\
\text { type }\end{array}$ & $\begin{array}{c}\text { Preheating } \\
\text { temperature } \\
\mathrm{T}_{\mathrm{p}} \text {, 践 }\end{array}$ & $\begin{array}{c}\text { Tempering } \\
\text { temperature } \\
\mathrm{T}_{\text {temp, }} \text {, } \mathrm{C}\end{array}$ \\
\hline \multirow{3}{*}{1} & \multirow{3}{*}{ GALEB 70} & 3.25 & $110-130$ & \multirow{3}{*}{$=(+)$} & \multirow{3}{*}{300} & \multirow{3}{*}{650} \\
\hline & & 4.0 & $130-160$ & & & \\
\hline & & 5.0 & $170-200$ & & & \\
\hline \multirow{3}{*}{2} & \multirow{3}{*}{ PIVA 352} & 3.25 & $100-130$ & \multirow{3}{*}{$=(+)$} & \multirow{3}{*}{300} & \multirow{3}{*}{650} \\
\hline & & 4.0 & $140-180$ & & & \\
\hline & & 5.0 & $180-230$ & & & \\
\hline \multirow[t]{3}{*}{3} & E DUR 300 & 3.25 & $100-135$ & \multirow{3}{*}{$=(+)$} & \multirow{3}{*}{300} & \multirow{3}{*}{650} \\
\hline & & 4.00 & $130-170$ & & & \\
\hline & & 5.00 & $180-220$ & & & \\
\hline
\end{tabular}

Table 4.

Parameters of the MAG hard-facing and estimated properties of the HAZ

\begin{tabular}{|c|c|c|c|c|c|c|c|}
\hline $\begin{array}{c}\text { Electrode } \\
\text { diameter } \\
\mathbf{m m}\end{array}$ & $\begin{array}{c}\text { Hard- } \\
\text { facing } \\
\text { current } \\
\boldsymbol{A}\end{array}$ & $\begin{array}{c}\text { Voltage } \\
\boldsymbol{V}\end{array}$ & $\begin{array}{c}\text { Hard-facing rate } \\
\mathbf{c m} / \mathbf{s}\end{array}$ & $\begin{array}{c}\text { Input } \\
\text { energy } \\
\mathbf{J} / \mathbf{c m}\end{array}$ & $\begin{array}{c}\text { Cooling } \\
\text { time } \mathbf{t}_{\mathbf{8} 5} \\
\mathbf{s}\end{array}$ & $\begin{array}{c}\text { HAZ } \\
\text { micro- } \\
\text { structure }\end{array}$ & $\begin{array}{c}\text { HAZ hardness } \\
\text { HV }\end{array}$ \\
\hline 3.25 & 110 & 24.5 & $\approx 0.124$ & 17387 & 17.3 & Martensite & $573-580$ \\
\hline 4.0 & 170 & 27 & $\approx 0.160$ & 22950 & 26.3 & Martensite & $573-580$ \\
\hline 5.00 & 200 & 28 & $\approx 0.169$ & 26509 & 32.6 & Martensite & $573-580$ \\
\hline
\end{tabular}

Based on the obtained results, it was concluded that the unfavorable structure and high hardness are obtained, regardless of the input energy. This is why it was necessary to execute the tempering after the hard-facing, so that the brittle martensite structure should be transformed into more favorable structures of higher plasticity.

After the theoretical considerations and prior to actual repair of the damaged mallet shown in Figure 1, the model investigations by hard-facing the samples of the similar material as the mallet's, were performed. The samples were preheated, then hard-faced by the adequate technology and afterwards tempered with different cooling rates. The laboratory tests were performed on the hard-faced samples and thus the optimal hard-facing technology was defined, that should be then applied for reparation of the mallet itself, Figure 1.
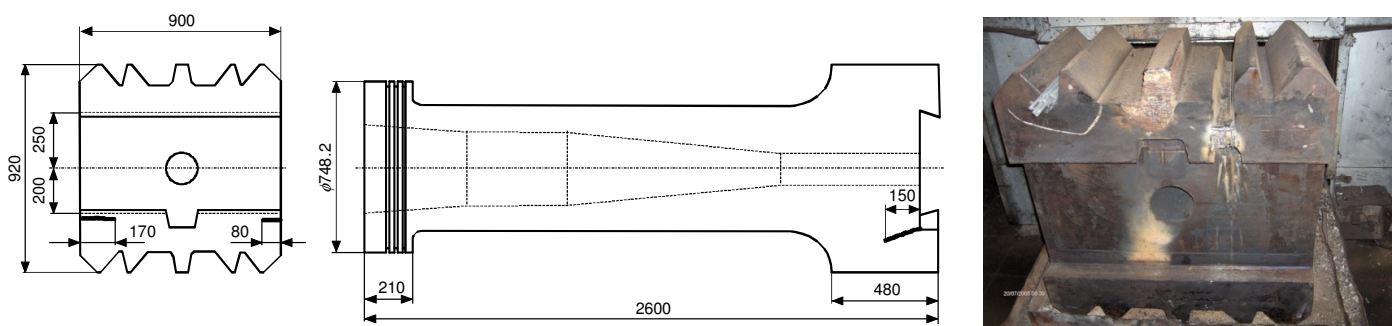

Fig. 1. Forging hammer's mallet with noticed cracks and appearance of the mallet during the reparation

It should be first preheated according to the precisely prescribed procedure. The unheated part is placed into the furnace, then heated with it until the desired temperature is reached and then kept at that temperature for a certain time. The cleaned part of the mallet that is to be hard-faced, is then pulled out from the heat-treatment furnace, Figure 1, and then repaired. The temperature must be maintained at the attained level during the whole process by the additional heat sources. The special tools, the "positioners" are used to enable that the hard-facing is done in the natural position - the "H" position. 


\subsection{Order of the operations during the mallet reparation}

- Prior to hard-facing, the basic electrodes should be dried according to manufacturer's recommendations;

- The root layers should be deposited by electrodes of the smaller diameter, while for the welds and covering layers should be used the larger diameter electrodes;

- The adequate block-sequences technology should be applied, both for the filling the groove and executing the final layers;

- Freshly deposited layers should be forged-out within the adequate temperature interval, by application of the special tool with the rounded tip;

- After each pass, the dross should be hammered-out and removed by the steel brushes;

- The preheating temperature should be controlled by the thermo-chalks or the special digital instrument with a thermocouple, or the contactless thermometer;

- The additional heating should be used for maintaining the required temperature;

- After the executed reparation and cooling, the mallet should be subjected to tempering, which consists of gradual heating up to the set temperature, heating-through at that temperature and slow cooling within the furnace down to the room temperature. The complete temperature cycles is shown in Figure 2, (Lazić et al., 2009).

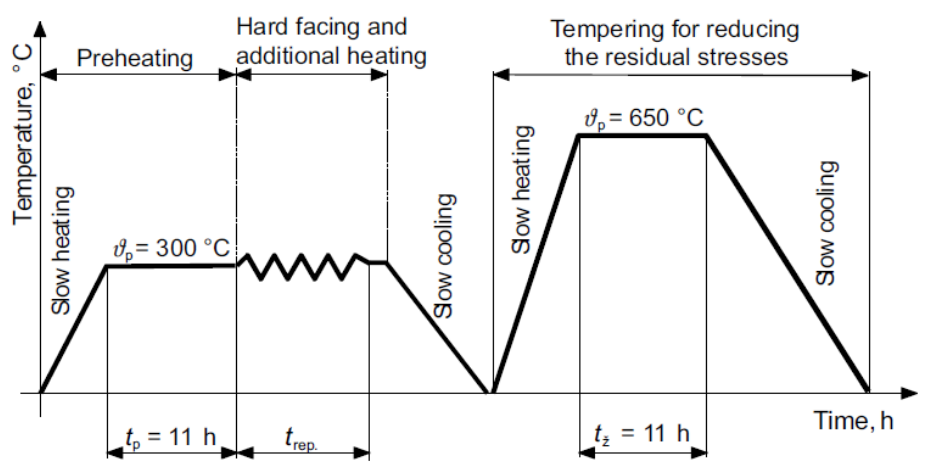

Fig. 2. The complete temperature cycles of the mallet's reparation

After the completed reparation cycle, the mallet is subjected to machining in order to restore its initial dimensions and shape. The whole process of the mallet reparation, Figure 3, that lasted several weeks, together with some previous experience of repairing the mallets and presses (Lazić et al., 2009; 2016), enabled obtaining the physical model of this complex procedure, which can serve as the guide-line for the future reparation processes of parts of the similar shape and dimensions. However, regardless of this fact, each individual reparation must be approached as a very responsible and complex problem, definitely not as a routine job. By application of the new knowledges, the optimal technologies and filler metals, it is realistic to expect multifold positive effects of the reparation processes, both direct and indirect ones.

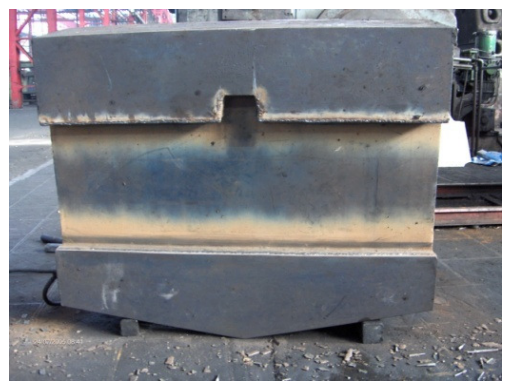

(a)

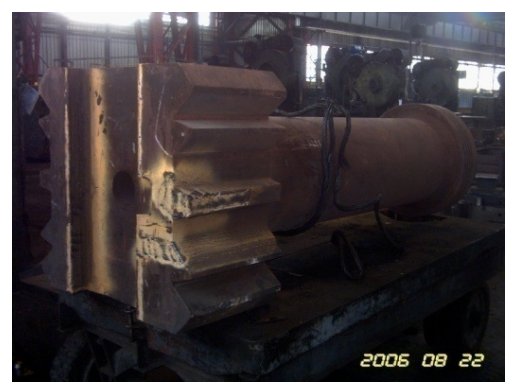

(b)

Fig. 3. Appearance of individual zones of the repaired mallet: (a) the hard-faced guides and (b) repaired teeth 


\section{CONCLUSIONS}

The successful reparation by hard-facing is only possible if that task is undertaken after the detailed analysis of causes of damages and selection of the technological parameters of the process. To obtain the reparation model it is necessary to perform the numerous experimental and model investigations, when the influence of the input parameters changes on the output properties of the executed operations are monitored. This is primarily related to the heat input and the cooling rate in the critical temperature interval.

The proposed reparation model, based on the previously established rank of individual parameters influences, was practically verified by the successful reparation of parts of various machine systems. In addition, this reparation model enables selection of the procedure and technology for hard-facing according to the required working conditions of the hard-faced parts and devices.

\section{ACKNOWLEDGEMENT}

This research was partially financially supported by European regional development fund and Slovak state budget by the project "Research Centre of the University of Žilina" and by the Ministry of Education, Science and Technological Development of Republic of Serbia through grants TR35024 and TR33015.

\section{REFERENCES}

Arsić, D., Lazić, V., Samardžić, I., Nikolić, R., Aleksandrović, S., Djordjević, M., Hadzima, B. (2015). Impact of the hard facing technology and the filler metal on tribological characteristics of the hard faced forging dies. Technical Gazette, 22(5), pp. 1353-1358.

Catalogues: Thyssen Marathon Edelstahl - Vosendorf, FEP-Plužine, Elvaco-Bijeljina, Železarna Jesenice-Fiprom, Bohler-Kapfenberg, Messer Griesheim-Frankfurt am Main, Esab-Göteborg, Lincoln Electric, USA, Atlas zur Wärmebehandlung der Stähle.

Jovanović, M., Adamović, D., Lazić, V. (1996). Welding technology, handbook. Faculty of Engineering, University of Kragujevac, Kragujevac (in Serbian).

Lazić, V., Jovanović, M. Rajačić, D., Josifović, D., Adamović, D. (1997). Surfacing of the truck lift hook. Welding and welded structures, 42(3), pp. 159-164.

Lazić, V. (2001). Optimization of the hard-facing process from the tribological aspects of the hard-faced layers and residual stresses. PhD. Faculty of Mechanical Engineering, Kragujevac.

Lazić, V., Jovanović, M., Josifović, D., Adamović, D., Ristović, J., Nedeljković, B. (2001). Influence of the heat treatment after the hard-facing on the working characteristics of the hard-faced forging tools. Welding and welded structures, 46(1-2), pp. 5-11.

Lazić, V., Jovanović, M., Adamović, D., Josifović, D., Ratković, N. (2006). Development and application of welding technologies for regeneration of damaged working parts of forging presses and hammers. In: Welding and Joining Technologies for a Sustainable Development and Environment, Timisoara, Romania, pp. 341-346.

Lazić, V., Sedmak, A., Aleksandrović, S., Milosavljević, D., Čukić, R., Grabulov, V. (2009). Reparation of damaged mallet for hammer forging by hard facing and weld cladding. Technical Gazette, 16(4), pp. 107-113.

Lazić, V., Čukić, R., Aleksandrović, S., Milosavljević, D., Arsić, D., Nedeljković, B., Djordjević, M. (2014). Techno-Economic Justification of Reparatory Hard Facing of Various Working Parts of Mechanical Systems. Tribology in Industry, 36(3), pp. 287-292.

Lazić, V., Arsić, D., Nikolić, R., Mutavdžić, M., Meško, J. (2016). Reparation by hard facing of the damaged secondary stone crushers. Manufacturing Technology, 16(2) pp. 375-380. 